\title{
Shear wave elastography and shear wave dispersion imaging in primary biliary cholangitis - a pilot study
}

\author{
Marten Schulz ${ }^{\#}$, Anne-Christin B. Wilde ${ }^{\#}$, Münevver Demir, Tobias Müller, Frank Tacke, Alexander \\ Wree
}

Department of Hepatology and Gastroenterology, Charité - Universitätsmedizin Berlin, Campus Virchow-Klinikum (CVK) and Campus Charité Mitte (CCM), Berlin, Germany

Contributions: (I) Conception and design: M Schulz, A Wree; (II) Administrative support: M Schulz, A Wree, T Müller, F Tacke; (III) Provision of study materials or patients: $\mathrm{AB}$ Wilde; (IV) Collection and assembly of data: M Schulz, AB Wilde, A Wree, M Demir; (V) Data analysis and interpretation: M Schulz, AB Wilde, A Wree; (VI) Manuscript writing: All authors; (VII) Final approval of manuscript: All authors.

\#The authors contributed equally to this work.

Correspondence to: Marten Schulz. Department of Hepatology and Gastroenterology, CVK, Charité Universitätsmedizin Berlin, Augustenburger Platz 1, 13353 Berlin, Germany. Email: marten.schulz@charite.de.

Background: Primary biliary cholangitis (PBC) is a chronic liver disease that can lead to liver fibrosis and cirrhosis. Two-dimensional shear wave elastography (2D-SWE) is a modern technique for fibrosis assessment. However, data regarding its performance in $\mathrm{PBC}$ is sparse. We aimed to characterize severity of liver disease in PBC patients using non-invasive 2D-SWE and the new methods of attenuation imaging (ATI) and shear wave dispersion imaging (SWD).

Methods: Twenty two PBC patients were examined with 2D-SWE, SWD and ATI, alongside established non-invasive fibrosis and steatosis assessment methods as well as liver function tests.

Results: Median 2D-SWE values were $1.48 \mathrm{~m} / \mathrm{s}$ (range, $1.14-2.13 \mathrm{~m} / \mathrm{s}$ ) and $6.7 \mathrm{kPa}$ (range, 3.8-14.7 kPa), respectively. Median SWD, ATI, transient elastography (TE) and controlled attenuation parameter (CAP) values were $13.9 \mathrm{~m} / \mathrm{s} / \mathrm{kHz}$ (range, $11.6-21 \mathrm{~m} / \mathrm{s} / \mathrm{kHz}$ ), $0.57 \mathrm{~dB} / \mathrm{cm} / \mathrm{MHz}$ (range, $0.5-0.68 \mathrm{~dB} / \mathrm{cm} / \mathrm{MHz}$ ), $7 \mathrm{kPa}$ (range, 3.7-14.6 kPa), and $208 \mathrm{~dB} / \mathrm{m}$ (range, 107-276 dB/m), respectively. 2D-SWE displayed a significant correlation with spleen length, platelet count, non-invasive fibrosis scores (FIB-4, APRI) and with TE. SWD correlated with alkaline phosphatase (ALP) levels, which is a prognostic marker in PBC.

Conclusions: Our findings add further evidence that 2D-SWE is a reliable method for fibrosis assessment in PBC. Even though the cohort size was small, the correlation of SWD with the prognostic marker ALP suggests a potentially valuable role of this new non-invasive method in evaluating liver disease activity in PBC.

Keywords: Primary biliary cholangitis (PBC); liver stiffness measurement (LSM); two-dimensional shear wave elastography (2D-SWE); attenuation imaging (ATI); shear wave dispersion imaging (SWD); transient elastography (TE)

Submitted Jun 23, 2021. Accepted for publication Sep 09, 2021.

doi: 10.21037/qims-21-657

View this article at: https://dx.doi.org/10.21037/qims-21-657

^ ORCID: 0000-0003-0298-0156. 


\section{Introduction}

Primary biliary cholangitis (PBC) is a chronic cholestatic liver disease that can lead to liver fibrosis and cirrhosis, with a rapid fibrosis progression without treatment (1). It is an autoimmune disease with detectable specific antimitochondrial antibodies (AMA) in up to $95 \%$ of $\mathrm{PBC}$ patients (2). Furthermore, alkaline phosphatase (ALP) is often chronically elevated. Based on treatment response, several scores such as the Barcelona (3) or Paris I (4) and II (5) criteria have been developed to evaluate the prognosis and the risk of developing complications such as cirrhosis and hepatocellular carcinoma (HCC).

Liver biopsy is considered the gold standard for the assessment of liver fibrosis and inflammation as surrogates for liver disease severity and prognosis. However, it is an expensive procedure that bears a small but relevant risk for complications such as bleeding, gall bladder perforation or pneumothorax (6). In recent years, non-invasive ultrasound (US)-based liver stiffness measurement (LSM) has been established as an effective method for liver fibrosis detection and staging in chronic liver diseases (7).

The most widely used LSM method is transient elastography (TE), which relies on a mechanical impulse that creates shear waves in the liver tissue. A receiver then evaluates shear wave propagation. TE has shown good diagnostic performance in PBC (8). More recently introduced LSM methods are point shear wave elastography (pSWE) and two-dimensional shear wave elastography (2D-SWE), which are integrated into conventional US systems. The latter allows real time imaging of shear wave propagation in the tissue under B-mode US vision control. A region of interest (ROI) can be placed at any localization in a colored elastogram and shear wave velocity, that correlates with tissue elasticity, can be measured. Results are displayed in meters per second $(\mathrm{m} / \mathrm{s})$ or converted into elasticity scores in kilopascals $(\mathrm{kPa})(9)$. Non-invasive LSM has also been investigated in $\mathrm{PBC}$ with varying results. Park et al. described a better diagnostic performance of a pSWE-method than laboratory-based liver fibrosis tests in patients with autoimmune liver disease (10). A German group investigated the accuracy of a pSWE system from another manufacturer in 26 PBC patients with lower histologic fibrosis stages and found no correlation with pSWE values (11).

Since nonalcoholic fatty liver disease (NAFLD) is the most common chronic liver disease (7), it can often be a relevant co-factor that can complicate other liver affections such as PBC. Therefore, it is necessary to detect and quantify steatosis in patients with chronic liver disease. TE enables the detection of controlled attenuation parameter (CAP), which is an accurate method for the quantification of hepatic fat accumulation (12). CAP uses an ultrasonic attenuation coefficient that estimates the ultrasonic attenuation on signals acquired by the TE system. Recently, a new method called attenuation imaging (ATI) has been introduced that also uses the attenuation of US beams as a surrogate parameter for the measurement of liver steatosis integrated in a conventional US system. Similar to 2D-SWE for fibrosis, ATI enables steatosis quantification over B-mode visualization of the area in which it is performed. The attenuation of US beams in the tissue is measured. Published results in NAFLD patients are promising $(13,14)$, but no comprehensive data exist in PBC.

Even more recently, a method called shear wave dispersion imaging (SWD) was introduced. In viscoelastic tissue, such as liver, shear wave speed varies depending on shear wave frequency. If a tissue is dispersive, the speed and the attenuation of shear waves will in-crease with frequency (15). Assessment of the dispersion slope of shear waves is directly linked to tissue viscosity. In preliminary studies, it has been suggested that liver viscosity as a surrogate for necroinflammatory activity in the liver can be quantified using SWD (15-17). Tzschätzsch et al. found that shear wave dispersion slope was significantly lower in healthy controls than in cirrhotic patients (18). Since this a novel method with only few published studies with a limited number of patients, its clinical applicability should still be interpreted with caution.

Taken together, published data on non-invasive LSM in PBC patients suggest that shear wave elastography might be an accurate tool for fibrosis detection in these patients. However, data is still sparse. Our study was aimed at providing further evidence in characterizing severity of liver disease in PBC patients using non-invasive SWE and the new methods of ATI and SWD.

We present the following article in accordance with the MDAR reporting checklist (available at https://dx.doi. org/10.21037/qims-21-657).

\section{Methods}

The study was conducted in accordance with the Declaration of Helsinki (as revised in 2013). The study was approved by the local Ethics Committees of the Universities of Berlin (EA2/035/07;03-2015) and twenty-two adult ( $>18$ years) patients with $\mathrm{PBC}$ from our 


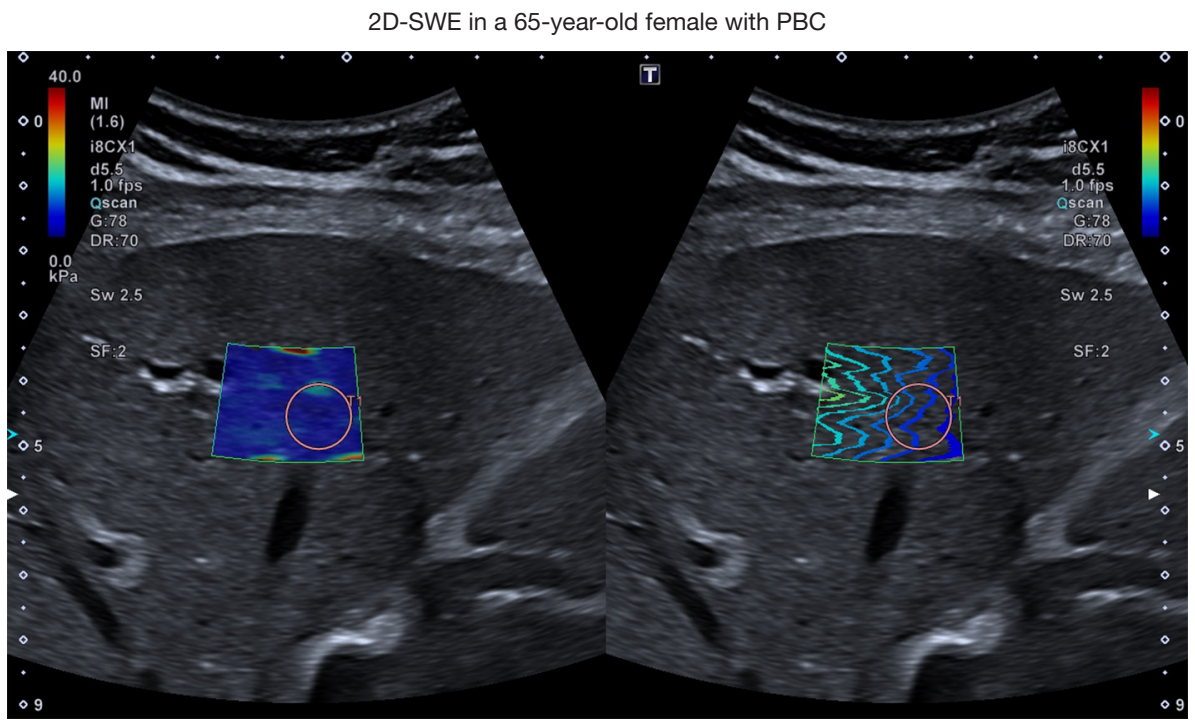

Figure 1 Lines on the right-hand side and a color map on the left-hand side, respectively visualize propagation of shear waves in the liver. A circular ROI is placed in the elastogram to measure stiffness. PBC, primary biliary cholangitis; ROI, region of interest.

outpatient clinic who gave written informed consent were included. PBC diagnosis was established according to EASL clinical practice guidelines on PBC [primarily taking into account elevated ALP and immunological markers such as antimitochondrial antibodies (AMA), anti-gp210 or anti-sp100] (19). Exclusion criteria were signs of right heart failure, cholestasis in US, viral hepatitis, excessive alcohol consumption ( $>30 \mathrm{~g} / \mathrm{d}$ in men, $>20 \mathrm{~g} / \mathrm{d}$ in women) or malignancy. Patients fasted for at least 4 hours and then underwent abdominal ultrasound (US) including grayscale US, Doppler measurement of the portal vein, spleen length measurement, 2D-SWE, SWD and ATI examination using Canon Aplio i800 US system (Canon Medical systems Corporation, Otawara, Tochigi, Japan). US examinations were conducted by an experienced sonographer with experience in liver US and sonoelastography $(>6,000 \mathrm{US}$, $>2,000$ SWEs). Furthermore, patients underwent TE and CAP measurement using Fibroscan ${ }^{\circledR}$ (Echosens, Paris, France) system.

\section{SWE}

Patients were examined in a supine position, 2D-SWE measurement was performed during a transient breath hold. In a right intercostal transducer position, shear wave propagation was observed in real-time visualization until image stabilization with a homogenous color filling and parallel lining of the elastogram was established in order to ensure reliable measurement quality. Large vessels and ascites were avoided according to the guidelines of the European Federation of Societies for Ultrasound in Medicine and Biology (EFSUMB). As recommended, an interquartile range/median (IQR/M) ratio $\leq 30 \%$ was defined as a criterion for a reliable measurement (9). A circular region of interest (ROI) with $1 \mathrm{~cm}$ diameter was then placed in the elastogram at least $1 \mathrm{~cm}$ below the liver capsule in a depth of 3 to $5 \mathrm{~cm}$ as depicted in Figure 1 . 2D-SWE value was calculated as a median of 5 reliable 2D-SWE measurements.

\section{$S W D$}

SWD analysis with at least 5 measurements was performed in the same manner as described above for 2D-SWE. Results were displayed in $\mathrm{m} / \mathrm{s} / \mathrm{kHz}$. Due to the scarcity of reference parameters, grading of inflammation according to cut-off levels is difficult. Sugimoto et al. recently proposed SWD cut-off values in a biopsy-controlled cohort of 111 individuals with suspected NAFLD patients (inflammation grade A1, inflammation grade $\mathrm{A} 2[\geq 9.9 \mathrm{~m} / \mathrm{s} / \mathrm{kHz}$, inflammation grade A3 [ $\geq 12.5 \mathrm{~m} / \mathrm{s} / \mathrm{kHz}]$ (16).

\section{ATI}

For ATI measurement, the transducer was placed in the same right intercostal position as described for SWE- 


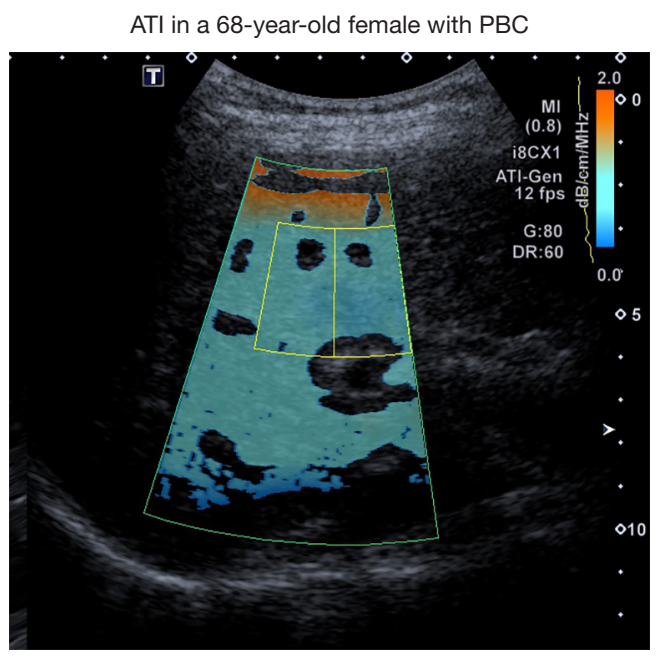

Figure 2 The yellow marked area within the color map represents the ROI. It is placed below the orange color that represents the artefact caused by the liver capsule. The attenuation coefficient was $0.54 \mathrm{~dB} / \mathrm{cm} / \mathrm{MHz}$ (no steatosis). $\mathrm{PBC}$, primary biliary cholangitis; ROI, region of interest.

acquisition using the same probe. Measurement was performed during a transient breath hold. ATI ROI was then placed below the orange colored area avoiding artifacts and large vessels as depicted in Figure 2. A median value of 5 measurements, each with a coefficient of determination $\geq 0.90$, was performed.

\section{$T E$}

For TE, the FibroScan ${ }^{\circledR}$ (Echosens, Paris, France) system was used. From a right intercostal position, a mechanical signal was emitted transcutaneously by a $3.5-\mathrm{MHz}$ probe (or a $2.5-\mathrm{MHz}$ probe in obese) and its propagation in the tissue, which correlates with elasticity, was measured by a receiver. Ten reliable measurements were performed in each patient (a success-rate of $\geq 60 \%$ and an interquartile range of $\leq 30 \%$ were mandatory), results were expressed in $\mathrm{kPa}$. Additionally, CAP was calculated in 10 reliable measurements.

\section{Laboratory results and fibrosis scores}

An extended routine liver panel was analyzed in all patients including among others: alanine aminotransferase (ALT), albumin, aspartate aminotransferase (AST), alkaline phosphatase (ALP), bilirubin, gamma-glutamyl transpeptidase (GGT), blood count and international normalized ratio (INR). Furthermore, laboratory-based fibrosis scores FIB-4 and APRI were determined. FIB-4 includes age, aminotransferases and platelets, whereas APRI encompasses AST and platelets (7).

\section{Statistical analysis}

Data collection and statistical analysis was performed with IBM SPSS Statistics for Windows (Version 27.0. Armonk, NY: IBM Corp.), using Pearson's correlation coefficient with a level of significance of $\mathrm{P}<0.05$ where appropriate.

\section{Results}

Twenty-two PBC patients were enrolled in the study. Patient characteristics are shown in Table 1. Twenty-one patients were female (95.5\%), 1 male (4.5\%). Median age was 61 years (range, $38-80$ years).

\section{Ultrasound examination}

US examination displayed a median spleen length of $99 \mathrm{~mm}$ $(\mathrm{n}=21)$. Doppler US showed a maximum portal vein velocity of $19 \mathrm{~cm} / \mathrm{s}(\mathrm{n}=20)$. In one patient, Doppler US did not display portal blood flow, a CT scan ruled out portal vein occlusion.

\section{D-SWE}

2D-SWE measurement displayed a median velocity of $1.48 \mathrm{~m} / \mathrm{s}$ (range, $1.14-2.13 \mathrm{~m} / \mathrm{s}$ ) and stiffness of $6.7 \mathrm{kPa}$ (range, $3.8-14.7 \mathrm{kPa}$ ).

\section{SWD and ATI}

SWD measurement displayed a median value of $13.9 \mathrm{~m} / \mathrm{s} / \mathrm{kHz}$ (range, $11.6-21 \mathrm{~m} / \mathrm{s} / \mathrm{kHz}$ ). Median ATI value was $0.57 \mathrm{~dB} / \mathrm{cm} / \mathrm{MHz}$ (range, $0.5-0.68 \mathrm{~dB} / \mathrm{cm} / \mathrm{MHz}$ ). Referring to ATI cut-off values proposed for a biopsycontrolled cohort of patients with various liver diseases, three patients had S1-steatosis, none exhibited more advanced steatosis (20).

\section{TE and CAP}

TE was performed in 20 patients (91\%), median value was $7 \mathrm{kPa}$ (range, 3.7-14.6 kPa). Based on PBC-specific 
Table 1 Patient characteristics, laboratory results, LSM findings and steatosis assessment

\begin{tabular}{|c|c|}
\hline Characteristics & Patients $(\mathrm{n}=22)$ \\
\hline \multicolumn{2}{|l|}{ Gender } \\
\hline Female & $21(95.5 \%)$ \\
\hline Male & $1(4.5 \%)$ \\
\hline Age (years) & $61[38-80]$ \\
\hline \multicolumn{2}{|l|}{ Laboratory findings } \\
\hline Total bilirubin (<1.2 mg/dL) & $0.46[0.2-4.66]$ \\
\hline ALT (<31 U/L) & 27.5 [13-69] \\
\hline AST (<35 U/L) & 32 [21-95] \\
\hline GGT (5-35 U/L) & $43.5[20-435]$ \\
\hline ALP (35-105 U/L) & 104.5 [68-331] \\
\hline Platelets (150-370/nL) & 202.5 [65-351] \\
\hline Albumin (35-52 g/L) & $42[31.9-47.6]$ \\
\hline Creatinine $(0.5-0.9 \mathrm{mg} / \mathrm{dL})$ & $0.8[0.56-1]$ \\
\hline INR 0.9-1.25 & 1 [0.96-3.55] \\
\hline \multicolumn{2}{|l|}{ US findings } \\
\hline PV maximum velocity $(\mathrm{cm} / \mathrm{s})$ & $19[12-30](n=20)$ \\
\hline Spleen length (mm) & $99[67-186](n=21)$ \\
\hline \multirow[t]{2}{*}{ 2D-SWE } & $1.48[1.14-2.13] \mathrm{m} / \mathrm{s}$ \\
\hline & $6.7[3.8-14.7] \mathrm{kPa}$ \\
\hline $\mathrm{SWD}(\mathrm{m} / \mathrm{s} / \mathrm{kHz})$ & $13[11.6-21]$ \\
\hline $\mathrm{TE}(\mathrm{kPa})$ & $7[3.7-14.6](n=20)$ \\
\hline ATI (dB/cm/MHz) & $0.57[0.5-0.68]$ \\
\hline $\mathrm{CAP}(\mathrm{dB} / \mathrm{m})$ & $208[107-276](n=16)$ \\
\hline \multicolumn{2}{|l|}{ Fibrosis scores } \\
\hline Fib-4 & $2.1[0.59-8.15]$ \\
\hline APRI & $0.4[0.2-4.2]$ \\
\hline
\end{tabular}

Data are given as median with range in square brackets if not stated otherwise. LSM, liver stiffness measurement; ALT, alanine aminotransferase; AST, aspartate aminotransferase; GGT, gamma-glutamyl transpeptidase; ALP, alkaline phosphatase; INR, international normalized ratio; US, ultrasound; PV, portal vein; 2D-SWE, two-dimensional shear wave elastography; SWD, shear wave dispersion; TE, transient elastography; ATI, attenuation imaging; CAP, controlled attenuation parameter. cut-offs (8), 5 patients were deemed to have F2 fibrosis, 2 patients $\mathrm{F} 3$ fibrosis and 3 patients $\mathrm{F} 4$ fibrosis. CAP measurements displayed a median level of $208 \mathrm{~dB} / \mathrm{m}$ (range, $107-276 \mathrm{~dB} / \mathrm{m})$. According to cut-off values proposed by Karlas et al. (21), one patient had S2 steatosis (out of $\mathrm{n}=16$ ). TE measurement was performed in a median time period of 2 months prior to 2D-SWE examination.

\section{Laboratory-based fibrosis scores and liver function tests}

Median FIB-4 and APRI were 2.1 (range, 0.59-8.15) and 0.4 (range, 0.2-4.2), corresponding to fibrosis stages F2 and F1, respectively.

Laboratory results are depicted in Table 1. Median total bilirubin was $0.46 \mathrm{mg} / \mathrm{dL}$, alanine aminotransferase (ALT) was $27.5 \mathrm{U} / \mathrm{L}$, aspartate aminotransferase (AST) was $32 \mathrm{U} / \mathrm{L}$, ALP median 104.5 U/L, gamma-glutamyl transpeptidase (GGT) 43.5 U/L, median platelets were $202.5 / \mathrm{nL}$, albumin was $42 \mathrm{~g} / \mathrm{L}$, creatinine was $0.8 \mathrm{mg} / \mathrm{dL}$ and INR was 1 .

\section{Correlation analysis}

Comparing 2D-SWE $(\mathrm{kPa})$ with fibrosis related markers such as spleen length and platelet count revealed significant correlations $(\mathrm{R}=0.661$ and $\mathrm{R}=-0.572$, respectively, $\mathrm{P}<0.05$ for both). Accordingly, correlations between 2D-SWE and fibrosis scores FIB-4 and APRI were significant $(\mathrm{R}=0.704$ and $\mathrm{R}=0.716$ respectively, $\mathrm{P}<0.05$ for both). Correlation of 2D-SWE $(\mathrm{m} / \mathrm{s}$ and $\mathrm{kPa})$ and TE was statistically significant ( $\mathrm{R}=0.745$ and $\mathrm{R}=0.732$ respectively, $\mathrm{P}<0.05$ for both).

SWD was significantly correlated with ALP and GGT ( $\mathrm{R}=0.537$ and $\mathrm{R}=0.494$ respectively, $\mathrm{P}<0.05$ for both). Results of linear correlation are displayed in Figure 3.

Besides with 2D-SWE, spleen length was also correlated with the fibrosis surrogates albumin, platelet count, FIB-4 and APRI $(\mathrm{R}=-0.514, \mathrm{R}=-0.615, \mathrm{R}=0.803$ and $\mathrm{R}=0.825$, respectively, $\mathrm{P}<0.05$ for all).

In the comparative analysis, we did not find a significant correlation of ATI with other parameters.

\section{Conclusions}

Non-invasive risk stratification is important in PBC. Besides disease-specific features such as biochemical response (e.g., ALP/bilirubin normalization), liver fibrosis stage is an independent predictor of outcome in patients with PBC (22). All applied techniques of fibrosis and steatosis assessment have been widely investigated in healthy volunteers and 

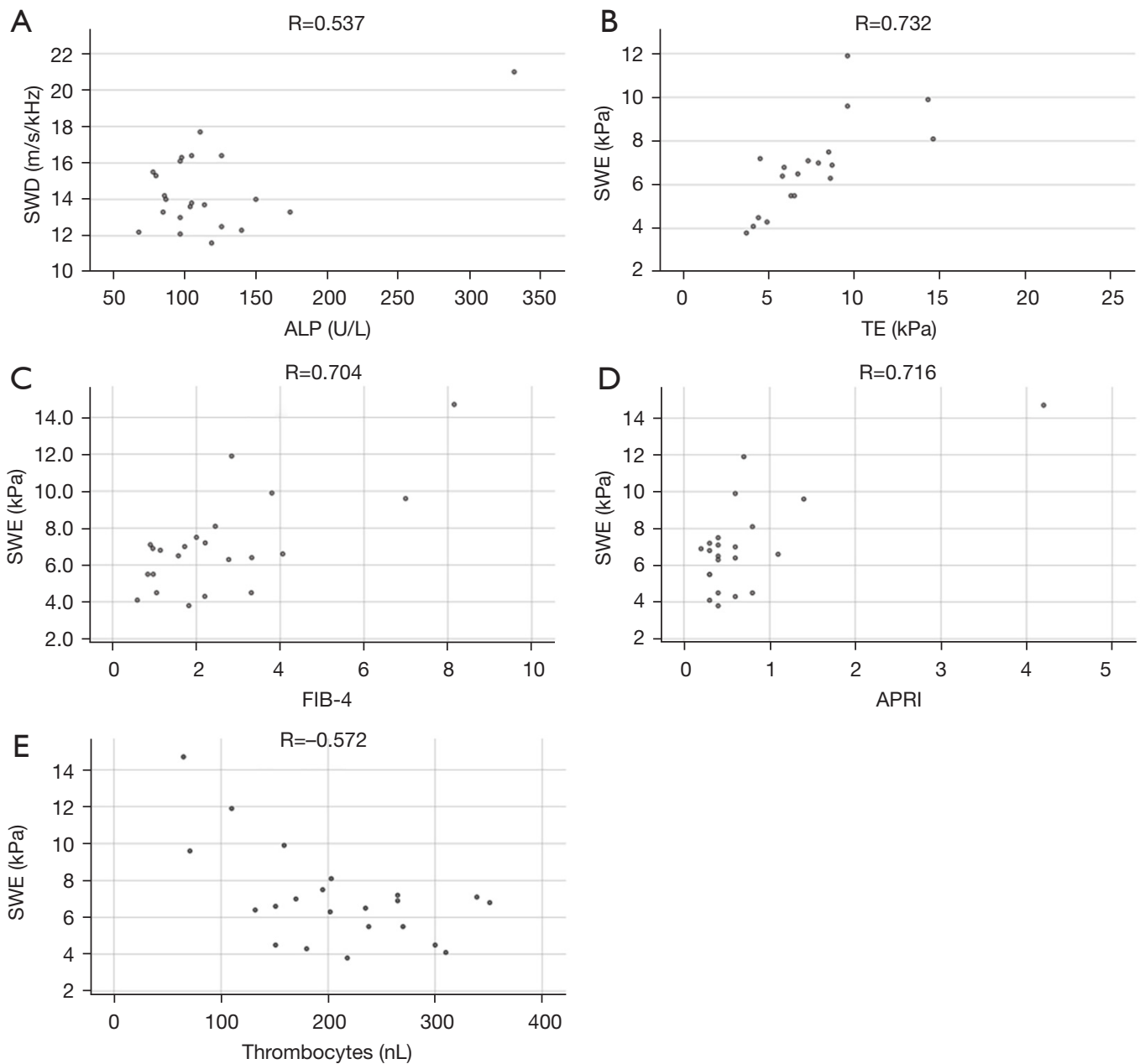

Figure 3 Correlation analysis between laboratory and imaging parameters. (A) Linear correlation of shear wave dispersion (SWD) and alkaline phosphatase (ALP); (B-E) Linear correlation of shear wave elastography (SWE) and transient elastography (TE), FIB-4 score, APRI score and thrombocytes/nL (nanoliter). All $\mathrm{P}$ values $<0.05$.

various liver diseases and particularly $\mathrm{TE}$ and CAP are recommended by guidelines $(9,23,24)$. As in NAFLD, TE is a well-established fibrosis assessment tool in PBC with disease-specific cutoffs (25), thereby serving as a reliable non-invasive reference method for 2D-SWE measurement. Published data on 2D-SWE in PBC is sparse. Recently, Yan et al. described a diagnostic accuracy for staging liver fibrosis of $73.9 \%$ comparing $2 \mathrm{D}-\mathrm{SWE}$ with histologic fibrosis assessment in 157 PBC patients using the Aixplorer US system (SuperSonic Imagine, Aix-en-Provence, France) (26). To our knowledge, our study is the first to address the Canon 2D-SWE system in PBC patients. We observed a significant correlation of 2D-SWE and various non-invasive liver fibrosis surrogate measurement tools such as TE (25) and fibrosis scores. Our findings support evidence that
2D-SWE is an accurate tool for liver stiffness determination in patients with $\mathrm{PBC}$. Of note, measurement of spleen length also correlated with multiple fibrosis markers underlining the importance of a conventional routine US in PBC patients.

Since $\mathrm{PBC}$ is characterized by an inflammatory destruction of intrahepatic bile ducts (27), detection and staging of inflammatory activity is crucial in the assessment of disease severity in PBC patients and may aid in treatment decisions. ALP serves as the most important prognostic laboratory parameter for liver disease evaluation in $\mathrm{PBC}$. We observed a significant correlation of SWD and ALP in our cohort suggesting that this new non-invasive method can be a helpful tool in assessing liver disease activity in PBC.

ATI measurement did not correlate with CAP, which also 
encourages further biopsy-controlled investigation of this method in PBC patients.

A limitation of this study is the small cohort size, so that results of this pilot study can only be interpreted as indicative. Furthermore, no histological correlation could be performed, which is in line with $\mathrm{PBC}$ guidelines that do not mandate routine biopsies in $\mathrm{PBC}$ patients for disease staging or grading $(19,28)$. Further research with larger cohorts and histological correlation in different underlying liver diseases is encouraged for a better understanding of the clinical impact of SWD and ATI. Both methods are new techniques that have not been investigated widely in chronic liver diseases and reliable reference values still need to be established.

Taken together, the results of this study indicate that the new technique of SWD can have a promising role in assessing (inflammatory) disease activity in PBC patients. Furthermore, our data support prior reports that 2D-SWE is a reliable method for fibrosis measurement in PBC. Since these non-invasive methods can be performed with little extra effort together with routine US, we believe that they have the potential of improving clinical management of $\mathrm{PBC}$ patients.

\section{Acknowledgments}

Funding: This study was supported by the German Research Foundation Grants MU 2864/1-3 and MU 2864/3-1.

\section{Footnote}

Reporting Checklist: The authors have completed the MDAR checklist. Available at https://dx.doi.org/10.21037/ qims-21-657

Conflicts of Interest: All authors have completed the ICMJE uniform disclosure form (available at https://dx.doi. org/10.21037/qims-21-657). ABW reports travel grants from Intercept Pharma, MSD and Novartis. The laboratory of FT. has received funding from Allergan, BMS, Inventiva and Gilead. FT has received honoraria or consulting fees from Allergan, Alnylam, Bayer, Gilead, BMS, Boehringer, Intercept, Ionis, Inventiva, Merz, Pfizer, NGM, CSL Behring, Novo Nordisk, Novartis, Falk. The consulting activities are unrelated to the current study. The other authors have no conflicts of interest to declare.

Etbical Statement: The authors are accountable for all aspects of the work in ensuring that questions related to the accuracy or integrity of any part of the work are appropriately investigated and resolved. The study was conducted in accordance with the Declaration of Helsinki (as revised in 2013). The study was approved by the local Ethics Committees of the Universities of Berlin (EA2/035/07; 03-2015) and informed consent was taken from all individual participants.

Open Access Statement: This is an Open Access article distributed in accordance with the Creative Commons Attribution-NonCommercial-NoDerivs 4.0 International License (CC BY-NC-ND 4.0), which permits the noncommercial replication and distribution of the article with the strict proviso that no changes or edits are made and the original work is properly cited (including links to both the formal publication through the relevant DOI and the license). See: https://creativecommons.org/licenses/by-nc-nd/4.0/.

\section{References}

1. Al-Harthy N, Kumagi T. Natural history and management of primary biliary cirrhosis. Hepat Med 2012;4:61-71.

2. Younossi ZM, Bernstein D, Shiffman ML, Kwo P, Kim WR, Kowdley KV, Jacobson IM. Diagnosis and Management of Primary Biliary Cholangitis. Am J Gastroenterol 2019;114:48-63.

3. Parés A, Caballería L, Rodés J. Excellent long-term survival in patients with primary biliary cirrhosis and biochemical response to ursodeoxycholic Acid. Gastroenterology 2006;130:715-20.

4. Corpechot C, Abenavoli L, Rabahi N, Chrétien Y, Andréani T, Johanet C, Chazouillères O, Poupon R. Biochemical response to ursodeoxycholic acid and long-term prognosis in primary biliary cirrhosis. Hepatology 2008;48:871-7.

5. Corpechot C, Chazouillères O, Poupon R. Early primary biliary cirrhosis: biochemical response to treatment and prediction of long-term outcome. J Hepatol 2011;55:1361-7.

6. Rockey DC, Caldwell SH, Goodman ZD, Nelson RC, Smith AD; American Association for the Study of Liver Diseases. Liver biopsy. Hepatology 2009;49:1017-44.

7. Schulz M, Tacke F. Identifying High-Risk NASH Patients: What We Know so Far. Hepat Med 2020;12:125-38.

8. Corpechot C, Carrat F, Poujol-Robert A, Gaouar F, Wendum D, Chazouillères O, Poupon R. Noninvasive elastography-based assessment of liver fibrosis progression and prognosis in primary biliary cirrhosis. Hepatology 2012;56:198-208.

9. Dietrich CF, Bamber J, Berzigotti A, Bota S, Cantisani V, 
Castera L, Cosgrove D, Ferraioli G, Friedrich-Rust M, Gilja OH, Goertz RS, Karlas T, de Knegt R, de Ledinghen V, Piscaglia F, Procopet B, Saftoiu A, Sidhu PS, Sporea I, Thiele M. EFSUMB Guidelines and Recommendations on the Clinical Use of Liver Ultrasound Elastography, Update 2017 (Long Version). Ultraschall Med 2017;38:e48.

10. Park DW, Lee YJ, Chang W, Park JH, Lee KH, Kim YH, Kang NK, Chung JW, Jang HY, Ahn S, Kim H, Jeong SH, Kim JW, Jang ES. Diagnostic performance of a point shear wave elastography (pSWE) for hepatic fibrosis in patients with autoimmune liver disease. PLoS One 2019; 14:e0212771.

11. Goertz RS, GaBmann L, Strobel D, Wildner D, Schellhaas B, Neurath MF, Pfeifer L. Acoustic Radiation Force Impulse (ARFI) Elastography in Autoimmune and Cholestatic Liver Diseases. Ann Hepatol 2019;18:23-9.

12. Piccinni R, Rodrigues SG, Montani M, Murgia G, Delgado MG, Casu S, Stirnimann G, Semmo N, De Gottardi A, Dufour JF, Berzigotti A. Controlled attenuation parameter reflects steatosis in compensated advanced chronic liver disease. Liver Int 2020;40:1151-8.

13. Dioguardi Burgio M, Ronot M, Reizine E, Rautou PE, Castera L, Paradis V, Garteiser P, Van Beers B, Vilgrain V. Quantification of hepatic steatosis with ultrasound: promising role of attenuation imaging coefficient in a biopsy-proven cohort. Eur Radiol 2020;30:2293-301.

14. Tada T, Iijima H, Kobayashi N, Yoshida M, Nishimura T, Kumada T, et al. Usefulness of Attenuation Imaging with an Ultrasound Scanner for the Evaluation of Hepatic Steatosis. Ultrasound Med Biol 2019;45:2679-87.

15. Sugimoto K, Moriyasu F, Oshiro H, Takeuchi H, Yoshimasu Y, Kasai Y, Itoi T. Clinical utilization of shear wave dispersion imaging in diffuse liver disease. Ultrasonography 2020;39:3-10.

16. Sugimoto K, Moriyasu F, Oshiro H, Takeuchi H, Abe M, Yoshimasu Y, Kasai Y, Sakamaki K, Hara T, Itoi T. The Role of Multiparametric US of the Liver for the Evaluation of Nonalcoholic Steatohepatitis. Radiology 2020;296:532-40.

17. Lee DH, Lee JY, Bae JS, Yi NJ, Lee KW, Suh KS, Kim H, Lee KB, Han JK. Shear-Wave Dispersion Slope from US Shear-Wave Elastography: Detection of Allograft Damage after Liver Transplantation. Radiology 2019;293:327-33.

18. Tzschätzsch H, Ipek-Ugay S, Trong MN, Guo J, Eggers J, Gentz E, Fischer T, Schultz M, Braun J, Sack I. Multifrequency time-harmonic elastography for the measurement of liver viscoelasticity in large tissue windows. Ultrasound Med Biol 2015;41:724-33.
19. European Association for the Study of the Liver. EASL Clinical Practice Guidelines: The diagnosis and management of patients with primary biliary cholangitis. J Hepatol 2017;67:145-72.

20. Bae JS, Lee DH, Lee JY, Kim H, Yu SJ, Lee JH, Cho EJ, Lee YB, Han JK, Choi BI. Assessment of hepatic steatosis by using attenuation imaging: a quantitative, easy-to-perform ultrasound technique. Eur Radiol 2019;29:6499-507.

21. Karlas T, Petroff D, Sasso M, Fan JG, Mi YQ, de Lédinghen $\mathrm{V}$, et al. Individual patient data meta-analysis of controlled attenuation parameter (CAP) technology for assessing steatosis. J Hepatol 2017;66:1022-30.

22. Murillo Perez CF, Hirschfield GM, Corpechot C, Floreani A, Mayo MJ, van der Meer A, et al. Fibrosis stage is an independent predictor of outcome in primary biliary cholangitis despite biochemical treatment response. Aliment Pharmacol Ther 2019;50:1127-36.

23. Gilligan LA, Trout AT, Bennett P, Dillman JR. Repeatability and Agreement of Shear Wave Speed Measurements in Phantoms and Human Livers Across 6 Ultrasound 2-Dimensional Shear Wave Elastography Systems. Invest Radiol 2020;55:191-9.

24. Sporea I, Bâldea V, Lupușoru R, Bende F, Mare R, Lazăr A, Popescu A, Șirli R. Quantification of Steatosis and Fibrosis using a new system implemented in an ultrasound machine. Med Ultrason 2020;22:265-71.

25. Corpechot C, El Naggar A, Poujol-Robert A, Ziol M, Wendum D, Chazouillères $\mathrm{O}$, de Lédinghen V, Dhumeaux D, Marcellin P, Beaugrand M, Poupon R. Assessment of biliary fibrosis by transient elastography in patients with PBC and PSC. Hepatology 2006;43:1118-24.

26. Yan Y, Xing X, Lu Q, Wang X, Luo X, Yang L. Assessment of biopsy proven liver fibrosis by two-dimensional shear wave elastography in patients with primary biliary cholangitis. Dig Liver Dis 2020;52:555-60.

27. Arndtz K, Hirschfield GM. The Pathogenesis of Autoimmune Liver Disease. Dig Dis 2016;34:327-33.

28. Lindor KD, Bowlus CL, Boyer J, Levy C, Mayo M. Primary Biliary Cholangitis: 2018 Practice Guidance from the American Association for the Study of Liver Diseases. Hepatology 2019;69:394-419.

Cite this article as: Schulz M, Wilde AB, Demir M, Müller T, Tacke F, Wree A. Shear wave elastography and shear wave dispersion imaging in primary biliary cholangitis-a pilot study. Quant Imaging Med Surg 2022;12(2):1235-1242. doi: 10.21037/qims-21-657 